Article

\title{
A Novel Passive Method for Regulating Both Air Temperature and Relative Humidity of the Microenvironment in Museum Display Cases
}

\author{
Meng Yu, Xuejun Zhang, Yang Zhao * and Xiaobin Zhang \\ Institution of Refrigeration and Cryogenics, Key Laboratory of Refrigeration and Cryogenic Technology \\ of Zhejiang Province, Zhejiang University, Hangzhou 310027, China; ym1993@zju.edu.cn (M.Y.); \\ xuejzhang@zju.edu.cn (X.Z.); zhangxbin@zju.edu.cn (X.Z.) \\ * Correspondence: youngzhao@zju.edu.cn
}

Received: 15 August 2019; Accepted: 30 September 2019; Published: 2 October 2019

\begin{abstract}
Display cases are widely utilized in museums to build an appropriate microenvironment for artifacts. In this study, a novel passive method is utilized to regulate both the temperature and relative humidity simultaneously of the microenvironment in museum display cases by proposing the concept of composite temperature and humidity control materials (CTHCM), which can be fabricated by combining both phase change material (PCM) and silica gel. The PCM is helpful to reduce the range of air temperature changes caused by melting or solidification processes, while the silica gel is helpful to reduce the range of relative humidity changes caused by adsorption or desorption processes. In this study, a coupled heat and mass transfer model is established to analyze the temperature-regulating and humidity-regulating performance of CTHCM using the software COMSOL Multiphysics. The influences of thermodynamic parameters of materials on temperature-regulating and humidity-regulating performance are also analyzed numerically. Results show that CTHCM is able to regulate the air temperature and relative humidity of the microenvironment in museum display cases effectively. It performs well in temperature-regulating as the phase change latent heat increases, and performs well in humidity-regulating as the water vapor permeability or moisture diffusivity increases.
\end{abstract}

Keywords: composite materials; museum display cases; temperature; relative humidity; coupled heat and mass transfer

\section{Introduction}

Artifacts in museums should be protected in a microenvironment with proper temperature, relative humidity, and illumination intensity to minimize their deterioration [1]. Research has shown that physical damage such as deformation and curl of cultural relics occurs due to different thermal expansion rates of materials [2]. The interface deformation of materials is different as the temperature changes. It is also reported that relative humidity values above $65 \%$ will lead to a microbial growth issue, while those below $25 \%$ will lead to brittleness or cracking issues [3]. As a result, large temperature or relative humidity fluctuations can easily cause dimensional deformation or mechanical destruction for organic materials, especially artifacts that are made from wood or paper. In museums, display cases are widely utilized to build an appropriate, stable, and safe microenvironment to protect artifacts [4].

There are mainly two types of methods for controlling the microenvironment in display cases: active control and passive control. The first type relies on devices to maintain the air temperature and relative humidity by heating, cooling, humidifying, and dehumidifying. Passive control methods concentrate on reducing the dynamics of air temperature and relative humidity based on improving the thermal inertia and/or hygroscopic capacity of the materials used in display cases. The passive 
control methods are more popular for situations where the artifacts are not very sensitive to air temperature and relative humidity, and are also cheaper and more convenient.

Humidity control materials were widely utilized in the fields of the chemistry industry, textiles, as well for cultural heritage protection. The materials have mostly been made from silica gels [5], minerals [6], charcoals [7], and so on. The specific standards to evaluate the humidity control capacities of relevant materials were firstly introduced by Morooka et al. [8]. The humidity-dependent capillary force was investigated by Xiao and Qian [9]. The response performance of porous glasses in low temperature environment was studied by Safronsky et al. [10]. The cycle operation of the TSA (thermal swing adsorption) cycle used for air dehumidification using silica gel as desiccant material has been investigated by Ramzy et al. [11] both experimentally and theoretically. The dynamics of heat and moisture transfer during dehumidification and regeneration processes have been analyzed in detail. The results indicated that the dehumidification cycle time is longer in the case of a smaller ratio of dehumidification to regeneration air flow rates. In addition, a smaller flow rate ratio is recommended for obtaining a lower air humidity ratio. Feng et al. [12] prepared an amorphous spherical silica-alumina beads material with a distinct bimodal pore structure by using sol-gel reactions of TEOS (tetraethoxysilane) and aluminum nitrate in the presence of PEO (polyethylene oxide). The appearance and structural properties of the material were investigated by digital camera, SEM (scanning electronic microscope), and TGA (thermal gravimetric analysis). The results showed that macroscopic spherical silica-alumina gel beads with a large specific surface area performed intelligent humidity control capacity and were able to keep the stage of relative humidity between $40 \%$ and $60 \%$ within $3 \mathrm{~h}$, which is a proper humidity range for the storage of most materials. An experimental setup was built by Ge et al. [13] to test TVOC as well as the humidity ratio removal capacity of a conventional silica gel desiccant wheel, and practical experiments were conducted under Shanghai summer conditions $\left(37^{\circ} \mathrm{C}, 65 \%\right.$ ) with a high TVOC concentration of $1.15 \mathrm{mg} / \mathrm{m}^{3}$. The results indicated that the moisture removal performance was greatly affected by an ambient humidity ratio but were kept fixed with the changing of the TVOC concentration, and the TVOC removal capacity was influenced both by an ambient humidity condition and by the contaminant concentration. Moreover, increasing research on improving the humidity control performance of humidity control materials has been carried out recently. The general method involves fabricating composite materials by combining various components which are useful for regulating the relative humidity.

It is common sense that materials with a larger specific heat capacity are easier to use to reduce the indoor temperature fluctuations. However, the thermal energy of such materials was stored as a result of a change in the storage material temperature, which was not sufficient to regulate the indoor temperature. Therefore, phase change materials (PCMs) have been widely applied in buildings because the thermal energy was stored as a result of a phase change process of the PCMs [14]. The temperature of the PCMs remains nearly constant in melting or solidification processes when PCMs absorb or release the indoor thermal heat. Consequently, PCMs can be utilized to regulate the indoor temperature of buildings [15]. PCMs have been used for thermal regulation in buildings since 1980 by adding the PCMs in gypsum board, plaster, concrete, or other wall covering materials [16]. A numerical and experimental investigation was carried out by Athienitis et al. to analyze the thermal performance of the PCMs-gypsum boards used in passive solar buildings [17]. Results indicated that the utilization of PCMs-gypsum boards exhibited potential for reducing overheating and energy consumption. Manz et al. experimentally investigated a TIM-PCMs external wall system for solar heating and day-lighting [18]. Results showed that positive influences on thermal performance could be found through the utilization of PCMs. Ismail and Castro numerically and experimentally studied the application of PCMs in walls and roofs of buildings [19]. They found that the addition of PCMs was beneficial for regulating the indoor temperature in buildings. Dardir et al. [20] investigated the utilization of a PCM-to-air heat exchangers system for building envelope applications that promoted thermal radiation loss to the sky during night-time to maximize the cooling potential. Experimental results showed that the thermal radiation to the sky during the cooling charging process of the PCM amplified the system's 
thermal losses, thereby increasing its cooling potential. The results also showed that the system promoted an increasing cooling charging potential under an insufficiently low air temperature and under no airflow conditions during the solidification of the PCM due to a magnified effect of the thermal radiation loss to the sky. Beltran and Gomez [21] analyzed a selection of PCM for building wallboards and roofs through a comparison between multi-criteria decision methods and building energy simulations. The results showed that PCM presented a good thermal behavior during day and night in cold places, especially at night, when the PCM maintains the indoor temperature at a constant comfortable temperature. In addition, the thermal performance during day and night was different in warm and humid places. Saxena et al. [22] experimentally studied the impact of PCM incorporated bricks, and assessed the change in temperature difference and heat flow across the bricks. The results showed a substantial reduction (up to $10^{\circ} \mathrm{C}$ ) in temperature fluctuation with PCM incorporated bricks. An inside temperature reduction between $4.5^{\circ} \mathrm{C}$ and $7{ }^{\circ} \mathrm{C}$, during the peak hours of the day, with respect to the conventional bricks, was observed.

The above research has indicated that the passive application of PCMs in buildings is able to improve the indoor thermal comfort level. However, to the authors' best knowledge, no reported research can be identified involving the application of PCMs to regulate temperature in the microenvironment, such as for display cases in museums.

In this study, the concept of composite temperature and humidity control materials (CTHCM) is proposed. CTHCMs can be synthesized using a vacuum impregnation method by taking PCMs as the temperature-regulating element and a porous medium as the humidity-regulating element. As a result, CTHCMs can regulate the temperature and relative humidity in display cases by absorbing or releasing heat and moisture. The main purpose of this study is to analyze the feasibility of composite temperature and humidity control materials (CTHCM) utilized in museum display cases to regulate both the temperature and relative humidity of microenvironment. A coupled heat and mass transfer model of CTHCM is firstly developed for comprehensive quantitative analysis using the software COMSOL Multiphysics. The influence of the main thermodynamic parameters of CTHCM on temperature-regulating and humidity-regulating performance is also analyzed. The results provide useful information and guidance to researchers for the regulation of the microenvironment in museum display cases using the passive control method.

\section{Simulation of the Proposed Method}

The heat and mass transfer process among the air inside the display case, the external air, and CTHCM, is shown in Figure 1. It can be observed from Figure 1 that the blue layer represents the CTHCM, while the white layer represents the air inside the display case. The objective of museum display case preservation of cultural relics is to maintain the air temperature and humidity inside the display case in a proper range. However, the microenvironment inside the display case can be easily influenced by the fluctuations of the external environment. The heat source fluctuation mainly comes from the temperature differences between the display case and the indoor environment in the museum building, which is represented as $\Delta Q$ in Figure 1 . The mass source fluctuation mainly comes from the air infiltration due to the poor encapsulation of the display case, which is represented by $\Delta W$ in Figure 1. Hence, CTHCM is utilized to regulate the temperature and relative humidity of the microenvironment in the display case. The CTHCM is able to regulate the air temperature inside the display case due to the temperature differences between the CTHCM and the air inside the display case, which is represented as $\Delta Q_{a d}$ in Figure 1. The CTHCM is able to regulate the air humidity inside the display case due to the water vapor partial pressure differences between the CTHCM and the air inside the display case, which is represented as $\Delta W_{a d}$ in Figure 1. It is worth noting that the objective of this study is mainly concentrated on the temperature and humidity control performance of CTHCM, not the heat and mass transfer on the air side. As a result, the CTHCM (blue layer) in Figure 1 is considered as the computational domain, while the air inside the display case (white layer) is considered 
as the boundary conditions of the coupled heat and mass transfer model of CTHCM established below. The geometrical parameters of CTHCM in this study are listed in Table 1.

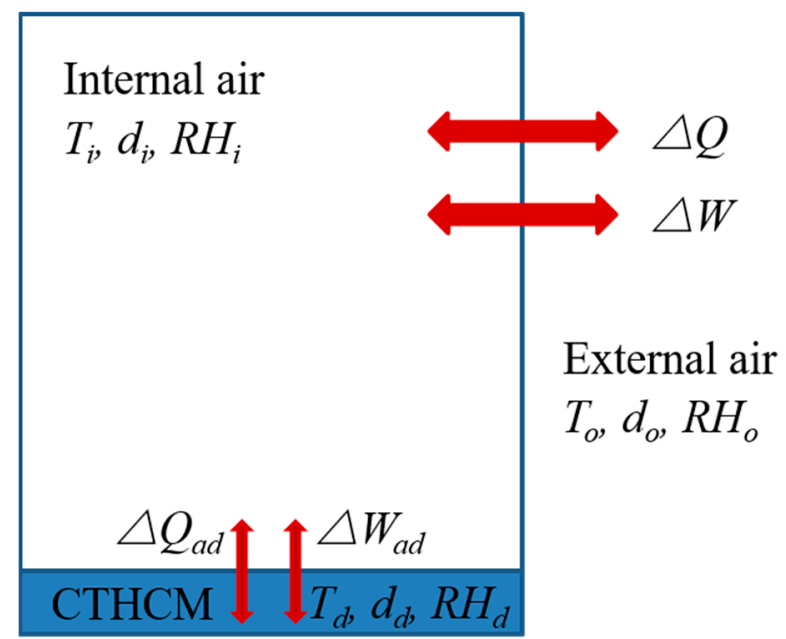

Figure 1. Heat and mass transfer process among the air inside the display case, the external air and composite temperature and humidity control materials (CTHCM).

Table 1. Geometrical parameters of the CTHCM in the museum display case.

\begin{tabular}{lll}
\hline No. & Parameter & Value \\
\hline 1 & Length $(L)$ & $0.8 \mathrm{~m}$ \\
2 & Width $(W)$ & $0.8 \mathrm{~m}$ \\
3 & Height $(H)$ & $0.1 \mathrm{~m}$ \\
\hline
\end{tabular}

A schematic diagram of CTHCM is shown in Figure 2. In this study, CTHCM is assumed to be a composite temperature and humidity control material synthesized by taking PCMs (such as paraffin) as the temperature-regulating element and porous media (such as silica gel) as the humidity-regulating element. Due to the temperature-regulating characteristic of the PCMs and the humidity-regulating characteristic of the porous media, heat and mass transfer occurs simultaneously in CTHCM. Several assumptions are listed below, in order to simplify the establishment of the numerical model in this study.

(1) CTHCM is a homogeneous and isotropic continuous medium in which the solid, liquid, and gas phases are always in thermodynamic equilibrium and the solid skeleton will not deform [23];

(2) the water vapor and the air in the pore can be treated as ideal gases, as a result, they all satisfy the ideal gas state equation [24];

(3) Thermodynamic properties such as density, specific heat capacity, and thermal conductivity of solid, liquid and gas phases are assumed as constants;

(4) Chemical reactions do not occur between heterogeneous substances [24];

(5) the influence of temperature on the moisture content of CTHCM is ignored [24];

(6) the hysteresis influence of hygroscopic characteristic on CTHCM is not considered [23];

(7) the performance of PCMs and porous media after being combined in CTHCM is assumed to be the same as before they were combined;

(8) the heat and mass transfer coefficients between the internal air and CTHCM are fixed as constants [25]. 


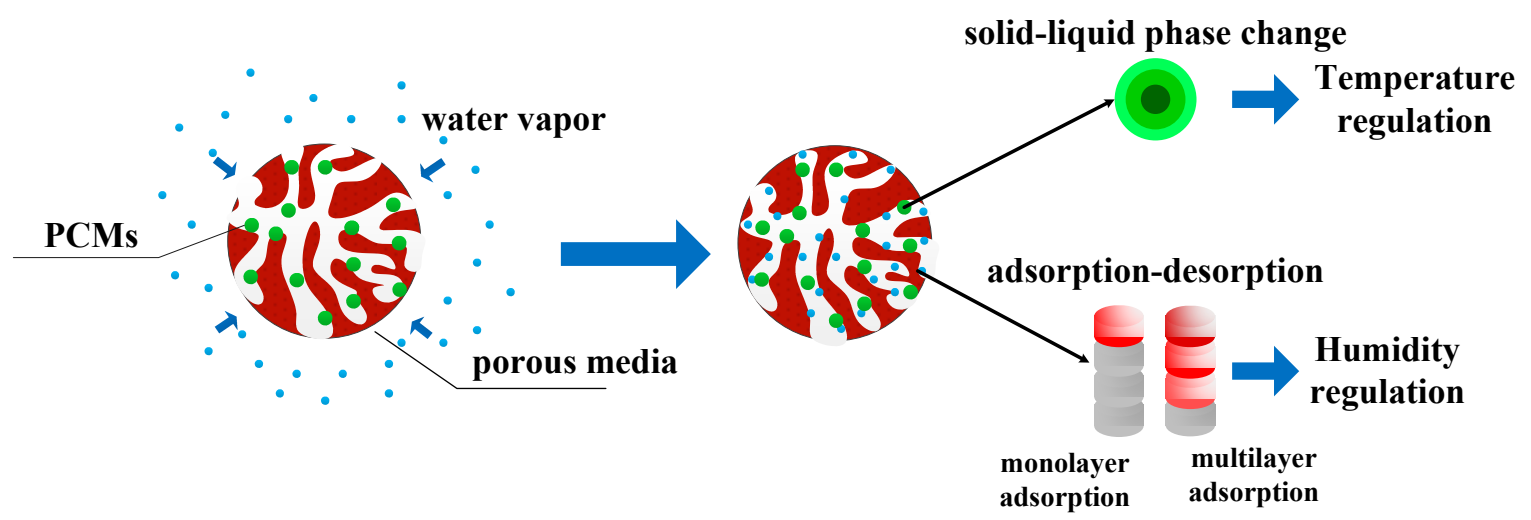

Figure 2. Schematic diagram of the temperature and humidity control principle of CTHCM.

\subsection{Governing Equations}

Based on the energy and mass conservation, the governing equations can be derived and listed as follows.

\subsubsection{Mass Transfer Equations}

In CTHCM, moisture can exist in the pores as two thermodynamic states: liquid and vapor phases. The mass conservation in CTHCM can be represented as Equation (1) [26].

$$
\rho_{\mathrm{m}} \frac{\partial \omega}{\partial t}=-\nabla\left(j_{\mathrm{v}}+j_{1}\right)
$$

where $\rho_{\mathrm{m}}\left(\mathrm{kg} / \mathrm{m}^{3}\right)$ is the density of CTHCM, $\omega(\mathrm{kg} / \mathrm{kg})$ is the moisture content of CTHCM, $t(\mathrm{~s})$ is the time, $j_{\mathrm{v}}\left(\mathrm{kg} / \mathrm{m}^{2} \cdot \mathrm{s}\right)$ is the vapor diffusion flux in CTHCM, and $j_{1}\left(\mathrm{~kg} / \mathrm{m}^{2} \cdot \mathrm{s}\right)$ is the liquid diffusion flux in CTHCM.

Depending on the driving forces that govern the model of transfer in porous material, moisture can pass in different forms and in different ways. For water vapor transport, the moisture driving potential is partial vapor pressure. The moisture driving potential for liquid water transport is capillary pressure. The diffusion of water vapor is generated by a vapor partial pressure gradient. As a result, the vapor diffusion flux can be described by Fick's law. Liquid water in a porous medium can be migrated under the effect of a capillary pressure gradient. As a result, the liquid diffusion flux can be described by Darcy's law. Finally, Equation (1) can be expressd as:

$$
\rho_{\mathrm{m}} \frac{\partial \omega}{\partial t}=\nabla\left(\delta_{\mathrm{v}} \nabla p_{\mathrm{v}}+\delta_{1} \nabla p_{\mathrm{c}}\right)
$$

where $\delta_{\mathrm{v}}(\mathrm{s})$ is the water vapor permeability of CTHCM, $p_{\mathrm{v}}(\mathrm{Pa})$ is the water vapor pressure in CTHCM, $\delta_{1}(\mathrm{~s})$ is the liquid water permeability of CTHCM, and $p_{\mathrm{c}}(\mathrm{Pa})$ is the capillary pressure in CTHCM.

It is a fact that the moisture content at the interface of the internal air and CTHCM is discontinuous. As a result, relative humidity $\varphi(\%)$ is selected as the driving potential of the mass transfer model due to its continuity.

The water vapor pressure in Equation (2) can be expressed as:

$$
p_{\mathrm{v}}=\varphi p_{\text {sat }}
$$

where $p_{\text {sat }}(\mathrm{Pa})$ is the saturated water vapor pressure in CTHCM which can be represented as a function of temperature $T(\mathrm{~K})$, according to the following empirical expression [24]:

$$
p_{\text {sat }}=\exp \left(65.8094-\frac{7066.27}{T}-5.976 \ln (T)\right) .
$$


At the pore scale, the equilibrium between the liquid and vapor phases can be described by Kelvin's law, which restricts the suction pressure to temperature and relative humidity. The capillary pressure is related to the relative humidity via Kelvin's law. As a result, the capillary pressure in Equation (2) can be represented as a function of temperature and relative humidity, which is shown in Equation (5):

$$
p_{\mathrm{c}}=-\rho_{\mathrm{l}} R_{\mathrm{D}} T \ln (\varphi)
$$

where $\rho_{1}\left(\mathrm{~kg} / \mathrm{m}^{3}\right)$ is the density of water and $R_{\mathrm{D}}(\mathrm{J} / \mathrm{kg} \cdot \mathrm{K})$ is the gas constant of water vapor.

The moisture content in Equation (1) also can be represented as a function of temperature and relative humidity, which is shown below.

$$
\frac{\partial \omega}{\partial t}=\frac{\partial \omega}{\partial \varphi} \frac{\partial \varphi}{\partial t}+\frac{\partial \omega}{\partial T} \frac{\partial T}{\partial t}
$$

According to assumption (5), Equation (6) can be simplified as:

$$
\frac{\partial \omega}{\partial t}=\frac{\partial \omega}{\partial \varphi} \frac{\partial \varphi}{\partial t}=k \frac{\partial \varphi}{\partial t}
$$

where $k$ is sorption capacity, which means the slope of sorption-moisture curve.

Finally, Equation (2) can be transformed into Equation (8), by using relative humidity and temperature as the driving forces:

$$
k \rho_{\mathrm{m}} \frac{\partial \varphi}{\partial t}=\nabla\left[\left(\delta_{\mathrm{v}} \varphi \frac{d p_{\mathrm{sat}}}{d T}+\delta_{1} \rho_{1} R_{\mathrm{D}} \ln (\varphi)\right) \nabla T+\left(\delta_{\mathrm{v}} p_{\mathrm{sat}}+\delta_{1} \rho_{1} R_{\mathrm{D}} \frac{T}{\varphi}\right) \nabla \varphi\right] .
$$

\subsubsection{Heat Transfer Equations}

The heat transfer equations are established based on the energy conservation law, which means the enthalpy in the meshes is equal to the energy flow into the meshes. The internal energy of the control volume is composed of the internal energy of the solid matrix of the CTHCM and the internal energy of the vapor and liquid phases contained in the pores of CTHCM. As a result, the energy conservation equation in CTHCM can be represented as follows:

$$
\frac{\partial}{\partial t}\left(\rho_{\mathrm{m}} c_{\mathrm{p}, \mathrm{m}} T+\rho_{\mathrm{m}} h_{\mathrm{v}} \omega_{\mathrm{v}}+\rho_{\mathrm{m}} h_{1} \omega_{1}\right)=-\nabla\left(q+h_{\mathrm{v}} j_{\mathrm{v}}+h_{1} j_{1}\right)
$$

where $c_{\mathrm{p}, \mathrm{m}}(\mathrm{J} / \mathrm{kg} \cdot \mathrm{K})$ is the specific capacity of CTHCM, $\omega_{\mathrm{v}}(\mathrm{kg} / \mathrm{kg})$ is the vapor moisture content of CTHCM, $\omega_{1}(\mathrm{~kg} / \mathrm{kg})$ is the liquid moisture content of CTHCM, $h_{\mathrm{v}}(\mathrm{J} / \mathrm{kg})$ is the enthalpy of water vapor, $h_{1}(\mathrm{~J} / \mathrm{kg})$ is the enthalpy of liquid water, $q\left(\mathrm{~W} / \mathrm{m}^{2}\right)$ is the heat conduction of CTHCM.

The enthalpy of water vapor can be obtained by the combination between the enthalpy of water vapor and the latent heat of vaporization.

$$
h_{\mathrm{v}}=h_{1}+h_{\mathrm{lv}}
$$

where $h_{\mathrm{lv}}(\mathrm{J} / \mathrm{kg})$ is the latent heat of vaporization.

The enthalpy of liquid water can be expressed as:

$$
h_{1}=c_{\mathrm{p}, 1} T
$$

where $c_{\mathrm{p}, 1}(\mathrm{~J} / \mathrm{kg} \cdot \mathrm{K})$ is the specific heat capacity of liquid water.

Equation (12) can be obtained by the transformations of the above equations, which is shown below.

$$
\rho_{\mathrm{m}}\left(c_{\mathrm{p}, \mathrm{m}}+\omega c_{\mathrm{p}, 1}\right) \frac{\partial T}{\partial t}=-\nabla\left(q+h_{\mathrm{lv}} j_{\mathrm{v}}\right)-c_{\mathrm{p}, 1}\left(j_{\mathrm{v}}+j_{1}\right) \nabla T-\rho_{\mathrm{m}} h_{\mathrm{lv}} \frac{\partial \omega_{\mathrm{v}}}{\partial t} .
$$


The heat conduction can be substituted by Equation (13) according to Fourier's law:

$$
q=-\lambda \nabla T
$$

where $\lambda(\mathrm{W} / \mathrm{m} \cdot \mathrm{K})$ is the thermal conductivity of CTMCM.

In Equation (12), the second term on the right side can be neglected since the sensible heat of water is much smaller than the latent heat of vaporization; the third term on the right side also can be neglected due to the poor changing rate of vapor content in CTHCM [27]. Finally, the heat transfer equation of CTHCM can be simplified as shown in Equation (14):

$$
\rho_{\mathrm{m}}\left(c_{\mathrm{p}, \mathrm{m}}+\omega c_{\mathrm{p}, 1}\right) \frac{\partial T}{\partial t}=\nabla\left[\left(\lambda+\delta_{\mathrm{v}} h_{\mathrm{lv}} \varphi \frac{d p_{\mathrm{sat}}}{d T}\right) \nabla T+\delta_{\mathrm{v}} h_{\mathrm{lv}} p_{\mathrm{sat}} \nabla \varphi\right]
$$

\subsection{Initial and Boundary Conditions}

The simulation models contain two parts: the internal air side and the CTHCM side. The initial conditions of the internal air and the CTHCM are listed in Table 2. The internal air remains in steady state in order to simplify the numerical calculation. The boundary conditions of the interface between the internal air and the CTHCM are as follows:

The moisture flow between the internal air and the CTHCM, $j\left(\mathrm{~kg} / \mathrm{m}^{2} \mathrm{~s}\right)$, can be expressed as:

$$
j=\rho_{\mathrm{a}} h_{\text {mass }}\left(\omega_{\mathrm{a}}-6.2 \times 10^{-6} \varphi p_{\text {sat }}\right)
$$

where $\rho_{\mathrm{a}}\left(\mathrm{kg} / \mathrm{m}^{3}\right)$ is the density of the internal air, $h_{\text {mass }}(\mathrm{m} / \mathrm{s})$ is the mass transfer coefficient at the interface, $w_{\mathrm{a}}(\mathrm{kg} / \mathrm{kg})$ is the humidity ratio of the internal air.

The heat flow between the internal and the CTHCM, $q\left(\mathrm{~W} / \mathrm{m}^{2}\right)$, can be expressed as:

$$
q=h_{\mathrm{a}}\left(T_{\mathrm{a}}-T\right)+\rho_{\mathrm{a}} h_{\mathrm{mass}}\left(\omega_{\mathrm{a}}-6.2 \times 10^{-6} \varphi p_{\mathrm{sat}}\right) h_{\mathrm{lv}}
$$

where $h_{\mathrm{a}}\left(\mathrm{W} / \mathrm{m}^{2} \cdot \mathrm{K}\right)$ is the heat transfer coefficient at the interface, $T_{\mathrm{a}}(\mathrm{K})$ is the temperature of the internal air.

The heat transfer coefficient, $h_{\mathrm{a}}$, is used for reference from the literature [28], $h_{\mathrm{a}}=8.72 \mathrm{~W} / \mathrm{m}^{2} \cdot \mathrm{K}$, and the mass transfer coefficient, $h_{\text {mass }}$, is calculated using the heat transfer coefficient, $h_{\mathrm{a}}$, according to the 'Lewis analogy' [29], which is shown as follows:

$$
h_{\text {mass }}=\frac{h_{\mathrm{a}}}{c_{\mathrm{p}, \mathrm{a}} \rho_{\mathrm{a}}}
$$

where $c_{\mathrm{p}, \mathrm{a}}(\mathrm{J} / \mathrm{kg} \cdot \mathrm{K})$ is the specific heat capacity of the internal air.

Table 2. Initial conditions of the internal air and the CTHCM.

\begin{tabular}{cll}
\hline Item & Parameter & Value \\
\hline \multirow{4}{*}{ Internal air } & Temperature $\left(T_{\mathrm{a}}\right)$ & $27^{\circ} \mathrm{C}$ \\
& Relative humidity $\left(\varphi_{\mathrm{a}}\right)$ & $65 \%$ \\
& Humidity ratio $\left(\omega_{\mathrm{a}}\right)$ & $0.015 \mathrm{~kg} / \mathrm{kg}$ \\
\hline \multirow{3}{*}{$\mathrm{CTHCM}$} & Temperature $(T)$ & $22^{\circ} \mathrm{C}$ \\
& Relative humidity $(\varphi)$ & $50 \%$ \\
& Humidity ratio $(\omega)$ & $0.008 \mathrm{~kg} / \mathrm{kg}$ \\
\hline
\end{tabular}

\subsection{Thermodynamic Properties of the Internal Air and the CTHCM}

CTHCM is a combination of PCMs and porous media, as a result, it is able to regulate the temperature and relative humidity individually. The performance of temperature-regulating and humidity-regulating 
is dependent on the material categories and combination proportions of PCMs and porous media. Due to the special characteristics of PCMs, an effective thermal capacity method is used in the simulation model [30]. The effective thermal capacity method is one of the most commonly-used mathematical methods for predicting the phase change heat transfer process. In this method, the phase change process is converted into a nonlinear heat transfer problem with a single phase. Therefore, for the PCM's phase state, sensible and latent heat will not be distinguished, and the PCM's effective thermal capacity value changing with its temperature is used in calculations. When taking CTHCM in this study as an example, the phase change latent heat and phase change temperature of CTHCM are $47376 \mathrm{~J} / \mathrm{kg}$ and $22{ }^{\circ} \mathrm{C}$, respectively. It is reasonable to define a small range around the phase change temperature, such as $21.5-22.5^{\circ} \mathrm{C}$. In this case, the equivalent heat capacity of CTHCM at $21.5-22.5^{\circ} \mathrm{C}$ can be considered as $47376 \mathrm{~J} / \mathrm{kg} \cdot \mathrm{K}$ based on the effective thermal capacity method. Since the CTHCM has not been successfully obtained by experimental preparation, it is unrealistic to directly measure the properties of CTHCM. Based on the assumption (7) above, the thermodynamic properties of CTHCM can be achieved by the material categories and combination proportions of PCMs and porous media. The definition of combination proportion of PCMs (e) is the ratio of the mass of PCMs to the total mass of CTHCM. In addition, the volume of CTHCM is the same as the volume of porous media, considering that the PCMs are impregnated into the porous media during the preparation of CTHCM. In this study, the hybrid material of cetane and octodecane is chosen as the PCMs, while silica gel is chosen as the porous media. Table 3 shows the thermodynamic properties used in the study [31-33]. Considering the melting and solidification temperature ranges of the hybrid material of cetane and octodecane, which is chosen as the PCMs, are nearly the same as the phase change temperature defined in Table 3, according to the thermodynamic properties provided by the manufacturer. As a result, the melting and solidification temperature ranges of the selected mixture of PCMs are simplified as the phase change temperature without influencing the final simulation results.

Table 3. Thermodynamic properties of the simulation models.

\begin{tabular}{|c|c|c|}
\hline Item & Parameter & Value \\
\hline \multirow{2}{*}{ Internal air } & Density $\left(\rho_{\mathrm{a}}\right)$ & $1.29 \mathrm{~kg} / \mathrm{m}^{3}$ \\
\hline & Specific heat capacity $\left(c_{\mathrm{p}, \mathrm{a}}\right)$ & $1004 \mathrm{~J} / \mathrm{kg} \cdot \mathrm{K}$ \\
\hline \multirow{5}{*}{ PCM } & Density $\left(\rho_{\mathrm{PCM}}\right)$ & $776 \mathrm{~kg} / \mathrm{m}^{3}$ \\
\hline & Specific heat capacity $\left(c_{\mathrm{p}, \mathrm{PCM}}\right)$ & $2001 \mathrm{~J} / \mathrm{kg} \cdot \mathrm{K}$ \\
\hline & Thermal conductivity $\left(\lambda_{\mathrm{PCM}}\right)$ & $0.13 \mathrm{~W} / \mathrm{m} \cdot \mathrm{K}$ \\
\hline & Phase change temperature $\left(T_{\mathrm{PCM}}\right)$ & $22{ }^{\circ} \mathrm{C}$ \\
\hline & Phase change latent heat $\left(h_{\mathrm{PCM}}\right)$ & $236880 \mathrm{~J} / \mathrm{kg}$ \\
\hline \multirow{3}{*}{ Porous media } & Density $\left(\rho_{\mathrm{pm}}\right)$ & $1200 \mathrm{~kg} / \mathrm{m}^{3}$ \\
\hline & Specific heat capacity $\left(c_{\mathrm{p}, \mathrm{pm}}\right)$ & $920 \mathrm{~J} / \mathrm{kg} \cdot \mathrm{K}$ \\
\hline & Thermal conductivity $\left(\lambda_{\mathrm{pm}}\right)$ & $0.3 \mathrm{~W} / \mathrm{m} \cdot \mathrm{K}$ \\
\hline \multirow[t]{17}{*}{ СТHCM } & Combination proportion of PCMs $(e)$ & 0.2 \\
\hline & Density $\left(\rho_{\mathrm{m}}\right)$ & $1976 \mathrm{~kg} / \mathrm{m}^{3}$ \\
\hline & Specific heat capacity $\left(c_{\mathrm{p}, \mathrm{m}}\right)$ & $1136 \mathrm{~J} / \mathrm{kg} \cdot \mathrm{K}$ \\
\hline & Thermal conductivity $\left(\lambda_{\mathrm{m}}\right)$ & $0.26 \mathrm{~W} / \mathrm{m} \cdot \mathrm{K}$ \\
\hline & Phase change temperature $\left(T_{\mathrm{m}}\right)$ & $22{ }^{\circ} \mathrm{C}$ \\
\hline & Phase change latent heat $\left(h_{\mathrm{m}}\right)$ & $47376 \mathrm{~J} / \mathrm{kg}$ \\
\hline & Sorption isothermal $(\omega)$ & $\omega=\frac{116}{\rho_{\mathrm{m}}\left(1-\frac{1}{0.118} \ln (\varphi)\right)^{0.869}} \mathrm{~kg} / \mathrm{kg}$ \\
\hline & Moisture diffusivity $\left(D_{\mathrm{w}}\right)$ & $6 \times 10^{-5} \mathrm{~m}^{2} / \mathrm{s}$ \\
\hline & Water vapor permeability $\left(\delta_{\mathrm{V}}\right)$ & $1 \times 10^{-8} \mathrm{~s}$ \\
\hline & Liquid water permeability $\left(\delta_{1}\right)$ & $\delta_{1}=\frac{\left(D_{\mathrm{w}} k-\delta_{\mathrm{v}} p_{\mathrm{sat}}\right) \varphi}{R_{\mathrm{D}} T \rho_{1}} \mathrm{~s}$ \\
\hline & Water density $\left(\rho_{1}\right)$ & $1000 \mathrm{~kg} / \mathrm{m}^{3}$ \\
\hline & Water specific heat capacity $\left(c_{\mathrm{p}, 1}\right)$ & $4200 \mathrm{~J} / \mathrm{kg} \cdot \mathrm{K}$ \\
\hline & Gas constant of water vapor $\left(R_{\mathrm{D}}\right)$ & $461.53 \mathrm{~J} / \mathrm{kg} \cdot \mathrm{K}$ \\
\hline & Saturated water vapor pressure $\left(p_{\text {sat }}\right)$ & $p_{\text {sat }}=\exp \left(65.8094-\frac{7066.27}{T}-5.976 \ln (T)\right) \mathrm{Pa}$ \\
\hline & Latent heat of evaporation $\left(h_{\mathrm{lv}}\right)$ & $2,500,000 \mathrm{~J} / \mathrm{kg}$ \\
\hline & Heat transfer coefficient $\left(h_{\mathrm{a}}\right)$ & $8.72 \mathrm{~W} / \mathrm{m}^{2} \cdot \mathrm{K}$ \\
\hline & Mass transfer coefficient ( $\left.h_{\text {mass }}\right)$ & $0.0067 \mathrm{~m} / \mathrm{s}$ \\
\hline
\end{tabular}




\subsection{Numerical Solution}

The established heat and mass transfer equations can be calculated simultaneously by using a computational tool COMSOL Multiphysics, in order to exhibit the temperature and relative humidity fields inside the CTHCM [34]. There is a partial differential equation (PDE) model in COMSOL Multiphysics, in order to solve equations that may not be solved by conventional models. It can be used to calculate four types of PDEs, including coefficient PDE, general PDE, weak PDE, and lower dimensions PDE. In this study, COMSOL Multiphysics of coefficient PDE was used to solve the coupled heat and mass transfer model of CTHCM with the constant time step of $0.1 \mathrm{~h}$ and constant grid number of 822 .

\section{Results and Discussion}

The simulation models from Section 2 are used to analyze the performance of CTHCM under various conditions. The constant structural and operating parameters adopted in the numerical investigation are summarized in Tables 1 and 2. The main objective of this study is to validate the feasibility of the composite temperature and humidity control material (CTHCM), hence, the performance comparison between CTHCM and conventional silica gel is essential. Moreover, thermodynamic parametric analysis of CTHCM is carried out, in order to optimize the temperature-regulating and humidity-regulating performance of CTHCM, and guide the selection and preparation of CTHCM. All of these research was conducted using numerical simulation, which is based on the coupled heat and mass transfer process of CTHCM. It is worth noting that the simulation environment is not the same as the actual environment in this study, as the temperature and relative humidity in the display cases are fixed as constants, which is impossible in reality. The purpose of doing this is to set an evaluating standard for the comparison of the performance between silica gel and CTHCM, and the optimization of the temperature-regulating and humidity-regulating performance of CTHCM. In fact, the PCMs and silica gel inside the CTHCM can barely reach saturation during the actual application in the museum display cases due to the continuous and incomplete absorption/desorption behaviors of both heat and moisture. The reason for this is that the heat and moisture loads of display cases in museums are small and fluctuating. For PCMs, the heat in the display cases can be absorbed by PCMs once the air temperature is higher than the phase change temperature of PCMs; the heat in the display cases can also be released by PCMs once the air temperature is lower than the phase change temperature of PCMs. Similarly, for silica gel, the moisture in the display cases can be absorbed by silica gel once the relative humidity is higher than the equivalent relative humidity of silica gel; the moisture in the display cases can also be released by silica gel once the relative humidity is lower than the equivalent relative humidity of silica gel.

No related experimental research can be used for the validation of the performance of CTHCM proposed in this study, since the concept of CTHCM is a novel one. Fortunately, the preparation and performance testing of CTHCM has been prepared. The further plan is to carry out an experimental study of CTHCM. In addition, the proposed model in this study can also be verified by using any hygroscopic materials. The reason is that the governing equations of CTHCM are the same as those of hygroscopic materials due to the utilization of effective thermal capacity method for PCMs in the simulation model. The only difference between them is the material property, which has no influence on the verification of the model. The established model has been verified by relevant experimental data from the literature $[35,36]$. The geometric model for validation has been built in the same way as the experimental setup from the literature. The initial and boundary conditions, and the thermodynamic properties of the material have been changed to be the same in the literature. Figure 3 shows the comparisons of the temperature and relative humidity between simulated data and experimental data during the adsorption and desorption tests. It could be concluded that the simulated data fitted the experimental data very well. As a result, the numerical model could be used for further case studies. 


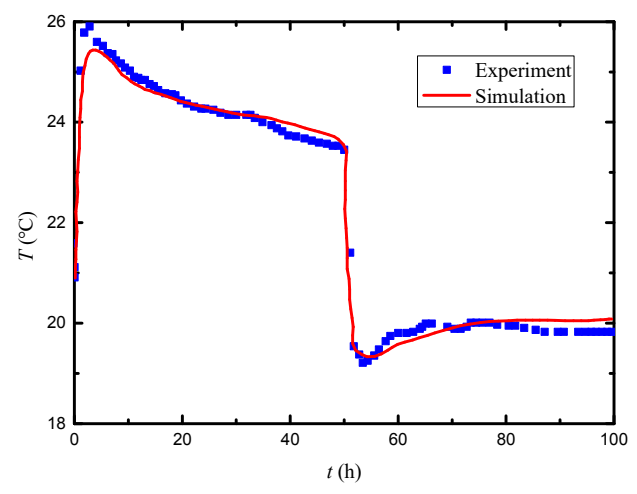

(a) temperature

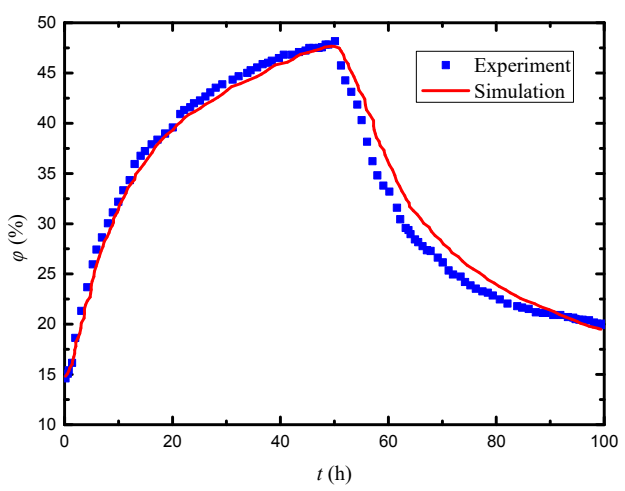

(b) relative humidity

Figure 3. Comparisons of the (a) temperature and (b) relative humidity between simulated data and experimental data during the adsorption and desorption tests.

\subsection{Performance Comparison between CTHCM and Silica Gel}

There are two main indicators for the temperature-regulating and humidity-regulating performance of CTHCM and silica gel: the temperature change rate and the relative humidity change rate. The slower the temperature change rate is, the better its temperature-regulating performance will be. Also, the faster the humidity change rate is, the better its humidity-regulating performance will be. The reason for this is that materials with larger heat and moisture capacity are able to regulate the constant hygrothermal environment for a long time, which results in a relatively slower temperature change rate and faster relative humidity change rate for the materials.

Figures 4 and 5 shows the temperature and relative humidity of CTHCM and silica gel with time growing under initial conditions. The monitoring point is located in the middle of CTHCM and silica gel. It can be observed that the temperature of CTHCM increases more slowly than that of silica gel over time. It can be seen that the temperature-regulating performance of CTHCM is higher than silica gel, which is because the temperature-regulating effect of CTHCM is a combination of sensible heat transfer and latent heat transfer, PCMs inside the pore of silica gel increase the temperature-regulating performance of CTHCM. In addition, it can be concluded that no distinct difference occurs between the relative humidity changes of both CTHCM and silica gel over time. As a result, PCMs inside the pore of silica gel will not affect the humidity-regulating performance of CTHCM. As the aim of such materials is to passively regulate the temperature and relative humidity of display cases in museums, and the advantage of CTHCM is more significant in temperature-regulating, it can be expected that CTHCM can obtain a better and more precise hygrothermal control effect than conventional silica gel.

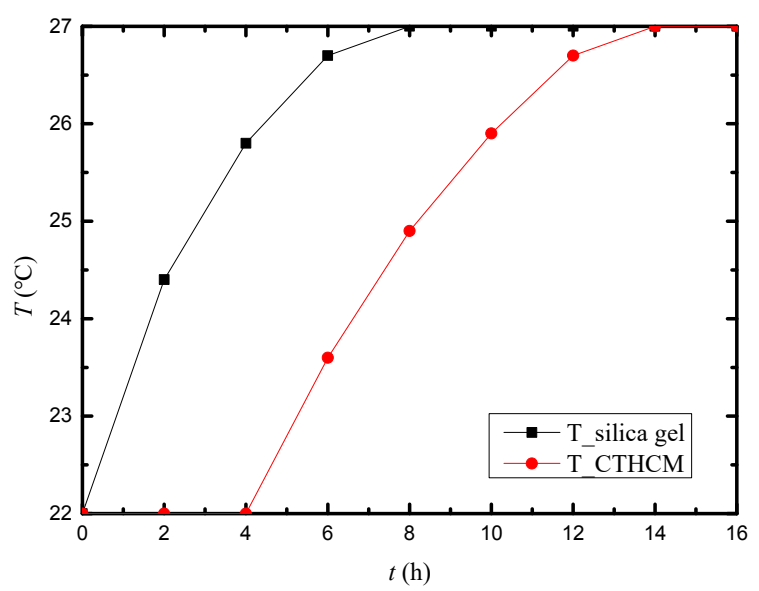

Figure 4. Comparison of temperature regulation capacity of CTHCM and silica gel in a display case. 


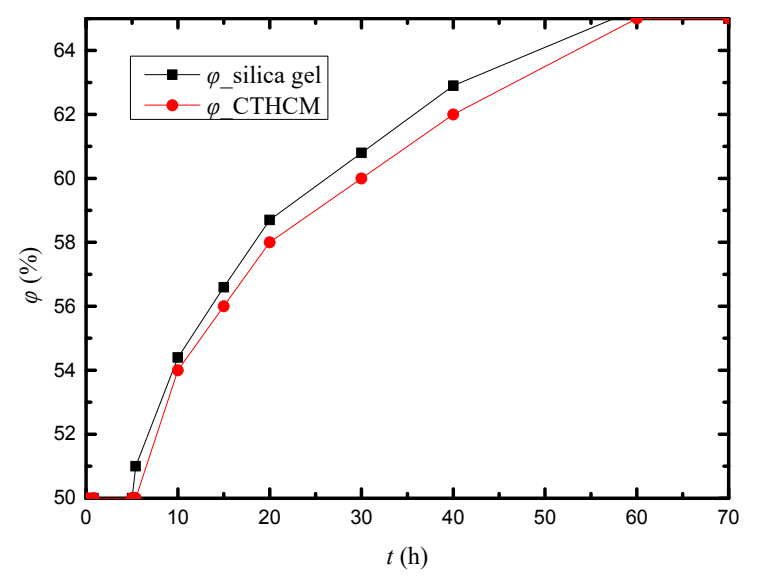

Figure 5. Comparison of relative humidity regulation capacity of CTHCM and silica gel in a display case.

\subsection{Influences of the Thermodynamic Parameters}

The phase change latent heat $h_{\mathrm{m}}$, water vapor permeability $\delta_{\mathrm{v}}$ and moisture diffusivity $D_{\mathrm{w}}$ are three significant parameters which can greatly affect the temperature-regulating and humidity-regulating performance of CTHCM. As a result, the established numerical model is applied to analyze their influences on the performance of CTHCM for further selection and optimization of materials. In the parametric study, one of the parameters is changed to analyze its influence while other parameters are fixed at the values shown in Table 3.

\subsubsection{Influence of the Phase Change Latent Heat}

Influence of the phase change latent heat on the temperature-regulating and humidity-regulating performance of CTHCM are described as shown in Figures 6 and 7, respectively. It can be found that the temperature change rate decreases with the increasing of $h_{\mathrm{m}}$. This means that the transient heat capacity increases. When $h_{\mathrm{m}}$ increases from $2.5 \times 10^{4} \mathrm{~J} / \mathrm{kg}$ to $4 \times 10^{5} \mathrm{~J} / \mathrm{kg}$, the time which is needed for the temperature to increase from $22{ }^{\circ} \mathrm{C}$ to $27^{\circ} \mathrm{C}$ is extended from about $12 \mathrm{~h}$ to $28 \mathrm{~h}$. That is to say, a larger $h_{\mathrm{m}}$ is helpful to absorb more thermal energy. This can be explained by the fact that more latent heat capacity can be included in CTHCM with larger $h_{\mathrm{m}}$, which results in the improvement of temperature-regulating performance. On the other hand, for the relative humidity, no obvious difference can be found with an increasing $h_{\mathrm{m}}$. Therefore, the phase change latent heat $h_{\mathrm{m}}$ has no influence on the humidity-regulating performance of CTHCM. In sum, a larger $h_{\mathrm{m}}$ can improve the temperature-regulating performance of CTHCM as well as having no side-effect on the humidity-regulating performance.

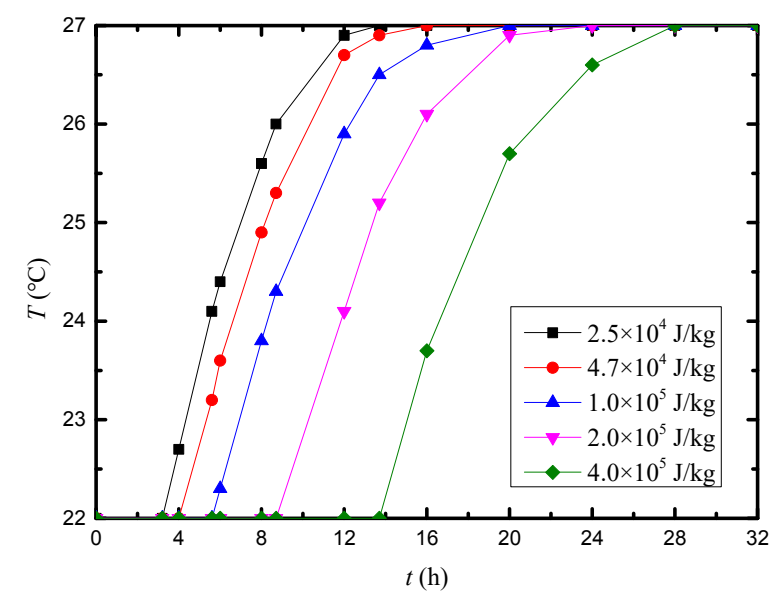

Figure 6. Influence of $h_{\mathrm{m}}$ on the temperature of CTHCM. 


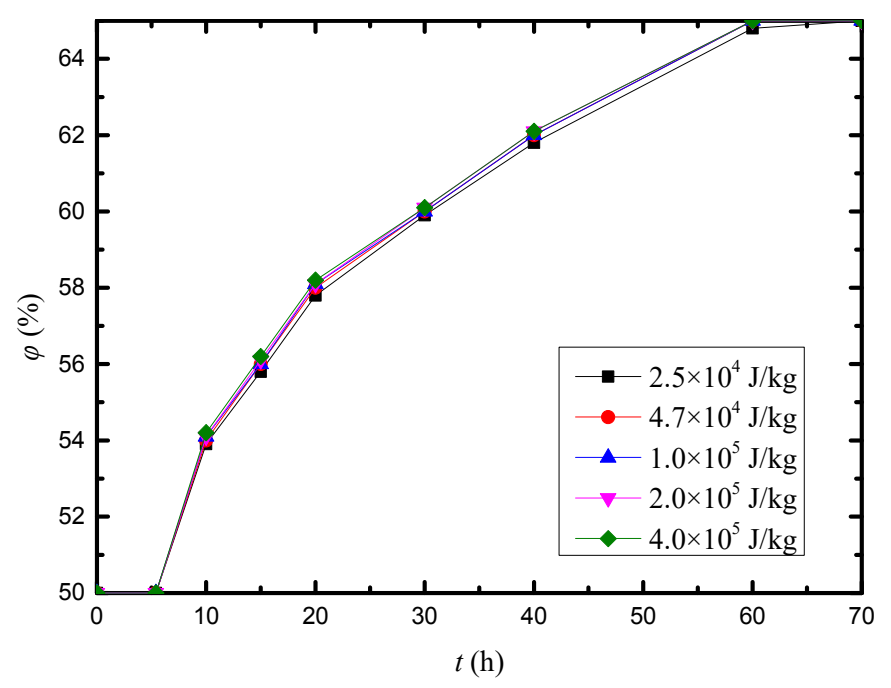

Figure 7. Influence of $h_{\mathrm{m}}$ on the relative humidity of CTHCM.

\subsubsection{Influence of Water Vapor Permeability}

The influence of water vapor permeability on the temperature-regulating and humidity-regulating performance of CTHCM is described as shown in Figures 8 and 9, respectively. It can be concluded that the relative humidity change rate increases with an increasing $\delta_{\mathrm{v}}$. When $\delta_{\mathrm{v}}$ increases from $1 \times 10^{-10} \mathrm{~s}$ to $1 \times 10^{-2} \mathrm{~s}$, the time which is needed for the relative humidity to increase from $50 \%$ to $65 \%$ is decreased from about $70 \mathrm{~h}$ to $43.6 \mathrm{~h}$. This is mainly due to the enhancement of mass transfer rate with increasing $\delta_{\mathrm{v}}$. Moreover, little temperature different fluctuation can be observed with increasing $\delta_{\mathrm{v}}$. That is to say the water vapor permeability $\delta_{\mathrm{v}}$ has no influence on the temperature-regulating performance of CTHCM. In conclusion, larger $\delta_{\mathrm{v}}$ is able to improve the humidity-regulating performance of CTHCM without affecting the temperature-regulating performance of CTHCM.

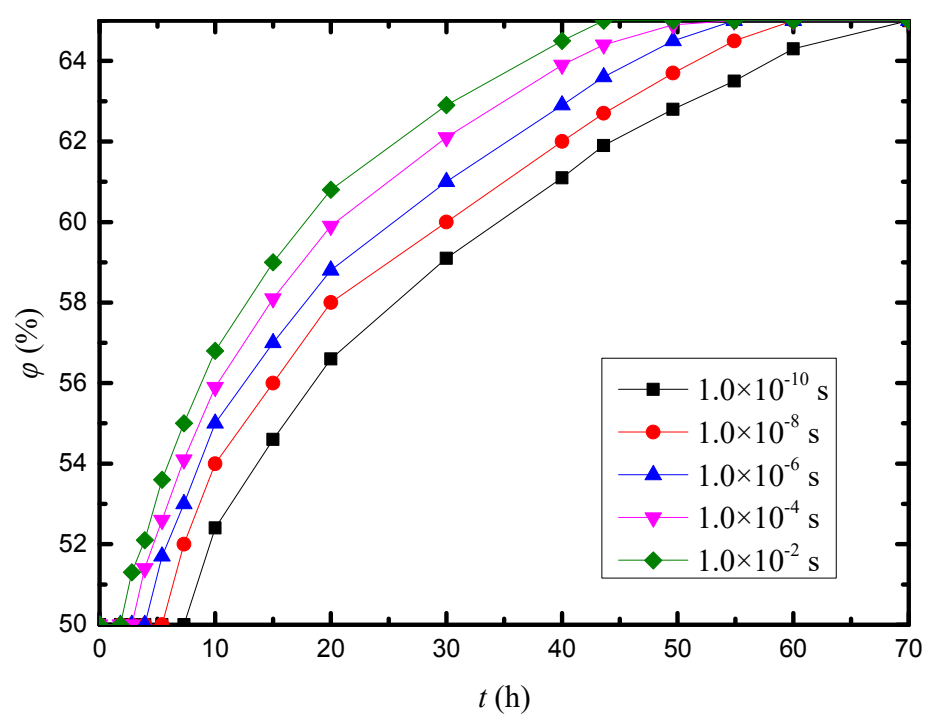

Figure 8. Influence of $\delta_{\mathrm{v}}$ on the relative humidity of CTHCM. 


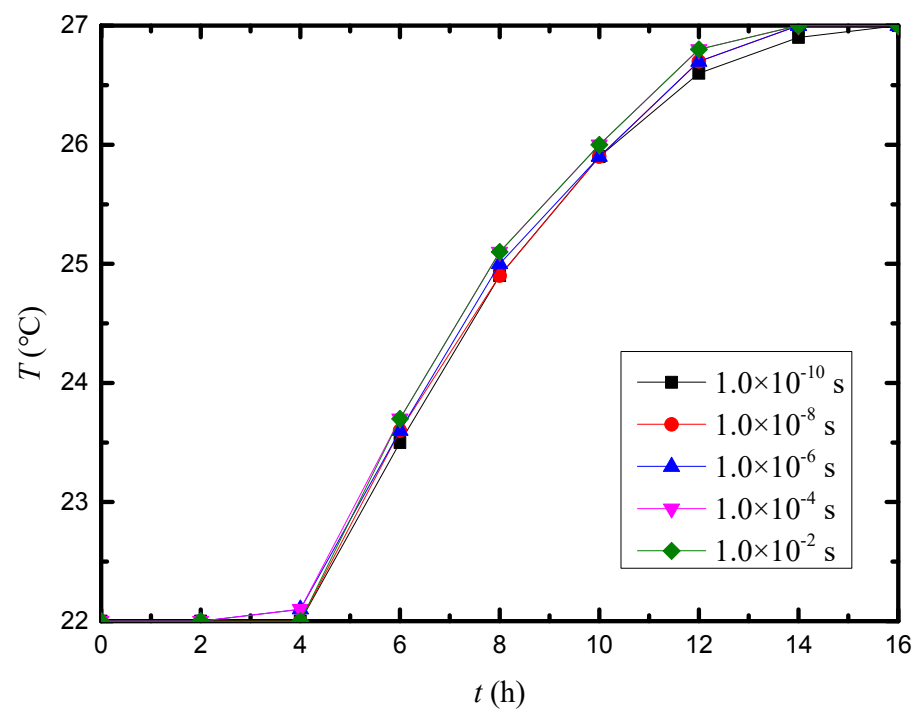

Figure 9. Influence of $\delta_{\mathrm{v}}$ on temperature of CTHCM.

\subsubsection{Influence of Moisture Diffusivity}

The temperature and relative humidity of CTHCM with respect to different values of $D_{\mathrm{w}}$ are simulated as illustrated in Figures 10 and 11. For the relative humidity, it is found that CTHCM with larger $D_{\mathrm{w}}$ has a better humidity-regulating ability over time. For example, when $D_{\mathrm{w}}$ increases from $6 \times 10^{-6} \mathrm{~m}^{2} / \mathrm{s}$ to $6 \times 10^{-2} \mathrm{~m}^{2} / \mathrm{s}$, the time which is needed for the relative humidity to increase from $50 \%$ to $65 \%$ is contracted from about $73 \mathrm{~h}$ to $42.7 \mathrm{~h}$. The results show that with the increasing $D_{\mathrm{w}}$, the liquid water permeability $\delta_{1}$ is also increased, which results in more moisture removal. For the temperature, it can be found that the temperature experiences different increases at a certain time as $D_{\mathrm{w}}$ increases, which indicates more heat is released during the heat transfer process when there is a larger $D_{\mathrm{w}}$. This is mainly due to the liquefaction of more water vapor as the liquid water permeability increases. When $D_{\mathrm{w}}$ increases from $6 \times 10^{-6} \mathrm{~m}^{2} / \mathrm{s}$ to $6 \times 10^{-2} \mathrm{~m}^{2} / \mathrm{s}$, the time which is needed for the temperature to increase from $22{ }^{\circ} \mathrm{C}$ to $27^{\circ} \mathrm{C}$ is contracted from about $16 \mathrm{~h}$ to $10 \mathrm{~h}$. As a result, under this specific condition, increasing $D_{\mathrm{w}}$ can improve the moisture capacity of CTHCM. However, the temperature-regulating ability is prone to be reduced due to the liquefaction of water vapor with an increasing $D_{\mathrm{w}}$, therefore a tradeoff should be made between the temperature-regulating performance and humidity-regulating performance of CTHCM.

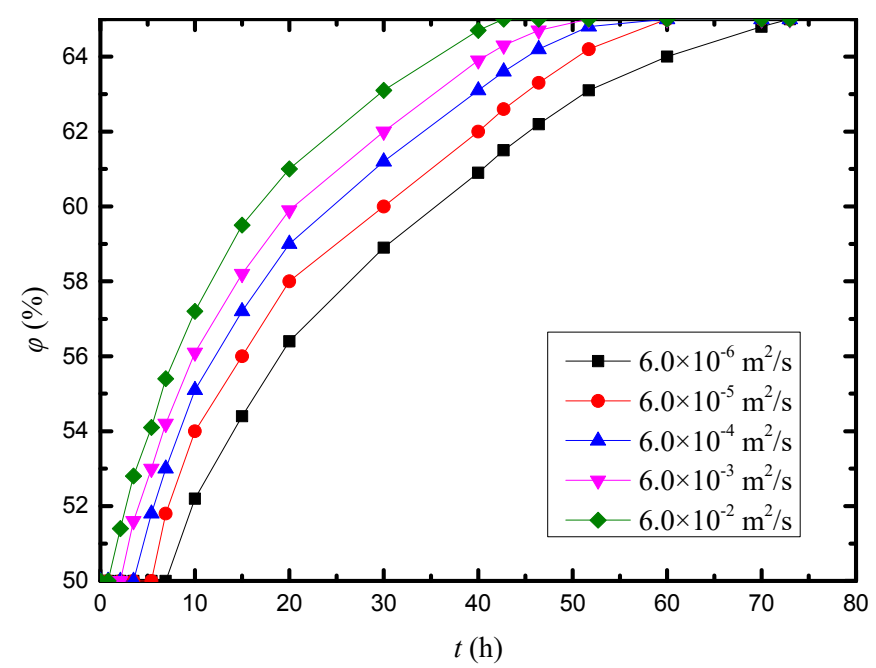

Figure 10. Influence of $D_{\mathrm{w}}$ on the relative humidity of CTHCM. 


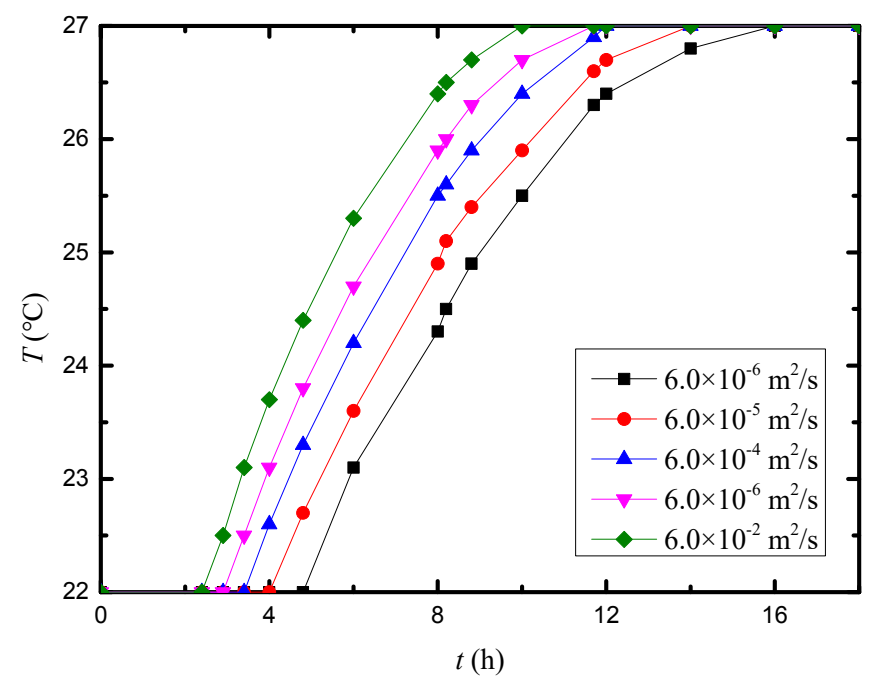

Figure 11. Influence of $D_{\mathrm{w}}$ on the temperature of CTHCM.

\section{Conclusions}

In this study, a novel passive method is proposed to regulate both the temperature and relative humidity simultaneously of the microenvironment in the museum display cases. It utilizes both PCM and silica gel. A dynamic mathematical model is developed to reveal the heat and mass transfer mechanism of CTHCM. Comprehensive comparisons are made based on the numerical simulation. The influence of the main thermodynamic parameters on temperature-regulating and humidity-regulating performance are also analyzed.

Results show that the proposed method can effectively improve the stability of the temperature and relative humidity in museum display cases. Its humidity-regulating performance is close to the that of only using silica gel. Under certain conditions, the temperature change rate is smaller than that of only using silica gel. The proposed method has a higher temperature-regulating capacity than the capacity when only using silica gel. The temperature-regulating capacity increases monotonically as the phase change to latent heat increases due to the enhancement of heat capacity. The humidity-regulating capacity increases monotonically as water vapor permeability or moisture diffusivity increases due to the enhancement of moisture capacity.

Author Contributions: Methodology, M.Y.; software, M.Y.; validation, M.Y.; investigation, X.Z. (Xuejun Zhang); resources, Y.Z.; data curation, X.Z. (Xiaobin Zhang); writing-original draft preparation, M.Y.; writing-review and editing, X.Z. (Xuejun Zhang), Y.Z., X.Z. (Xuejun Zhang); funding acquisition, Y.Z.

Funding: The research for this study was sponsored by the Cultural Relics Protection Technology Projects of Zhejiang Bureau of Cultural Heritage (Grant No. 2015012 and No. 2018005).

Conflicts of Interest: The authors declare no conflict of interest.

\section{Nomenclature}

$\begin{array}{ll}c_{\mathrm{p}} & \text { specific heat capacity, } \mathrm{J} / \mathrm{kg} \cdot \mathrm{K} \\ D_{\mathrm{w}} & \text { moisture diffusivity, } \mathrm{m}^{2} / \mathrm{s} \\ e & \text { combination proportion of PCMs } \\ h & \text { enthalpy, } \mathrm{J} / \mathrm{kg} \\ h_{\mathrm{a}} & \text { heat transfer coefficient, } \mathrm{W} / \mathrm{m}^{2} \cdot \mathrm{K} \\ h_{\mathrm{mass}} & \text { mass transfer coefficient, } \mathrm{m} / \mathrm{s} \\ H & \text { height of CTHCM, } \mathrm{m} \\ j & \text { diffusion flux, } \mathrm{kg} / \mathrm{m}^{2} \cdot \mathrm{s} \\ k & \text { sorption capacity, } \mathrm{kg} / \mathrm{kg} \\ L & \text { length of CTHCM, m } \\ p & \text { pressure, } \mathrm{Pa}\end{array}$




$\begin{array}{ll}q & \text { heat conduction, } \mathrm{W} / \mathrm{m}^{2} \\ R_{\mathrm{D}} & \text { gas constant of water vapor, } \mathrm{J} / \mathrm{kg} \cdot \mathrm{K} \\ t & \text { time, } \mathrm{s} \\ T & \text { temperature, } \mathrm{K} \\ W & \text { width of } \mathrm{CTHCM}, \mathrm{m} \\ \mathrm{Greek} & \\ \rho & \text { density, } \mathrm{kg} / \mathrm{m}^{3} \\ \omega & \text { moisture content, } \mathrm{kg} / \mathrm{kg} \\ \delta & \text { permeability, } \mathrm{s} \\ \varphi & \text { relative humidity } \\ \lambda & \text { thermal conductivity, } \mathrm{W} / \mathrm{m} \cdot \mathrm{K} \\ \text { Subscript } & \\ \mathrm{a} & \text { air } \\ \mathrm{C} & \text { capillary } \\ 1 & \text { liquid water } \\ \mathrm{lv} & \text { latent heat of evaporation } \\ \mathrm{m} & \text { CTHCM } \\ \text { pm } & \text { porous media } \\ \text { PCM } & \text { phase change material } \\ \text { sat } & \text { saturation } \\ \mathrm{v} & \text { vapor }\end{array}$

\section{References}

1. Lucchi, E. Review of preventive conservation in museum buildings. J. Cult. Herit. 2018, 29, 180-193. [CrossRef]

2. Zhang, W.J.; Li, J.Q.; Li, H.F.; Jiang, S.C.; An, L.J. Temperature dependence of deformation behavior of poly(butylene terephthalate). Polymer 2018, 143, 309-315. [CrossRef]

3. Zitek, P.; Vyhlidal, T. Model-based moisture sorption stabilization in historical buildings. Build. Environ. 2009, 44, 1181-1187. [CrossRef]

4. Schieweck, A.; Salthammer, T. Indoor air quality in passive-type museum showcases. J. Cult. Herit. 2011, 12, 205-213. [CrossRef]

5. Tomita, Y.; Takahashi, R.; Sato, S.; Sodesawa, T.; Otsuda, M. Humidity control ability of silica with bimodal pore structures prepared from water glass. J. Ceram. Soc. Jpn. 2004, 112, 491-495. [CrossRef]

6. Gao, N.F.; Kume, S.; Watari, K. Zeolite-carbon composites prepared from industrial wastes: (I) Effects of processing parameters. Mater. Sci. Eng. A 2005, 399, 216-221. [CrossRef]

7. Hasegawa, T.; Iwasaki, S.; Shibutani, Y.; Abe, I. Preparation of superior humidity-control materials from kenaf. J. Porous Mater. 2009, 16, 129-134. [CrossRef]

8. Morooka, T.; Homma, Y.; Norimoto, M. Criterion for estimating humidity control capacity of materials in a room. J. Wood Sci. 2007, 53, 192-198. [CrossRef]

9. Xiao, X.D.; Qian, L.M. Investigation of humidity-dependent capillary force. Langmuir 2000, 16, 8153-8158. [CrossRef]

10. Safronsky, E.D.; Roizin, Y.O.; Rysiakiewicz-Pasek, E. Application of porous glasses for humidity control. Opt. Mater. 1996, 5, 217-220. [CrossRef]

11. Ramzy, A.K.; Kadoli, R.; Ashok Babu, T.P. Experimental and theoretical investigations on the cyclic operation of TSA cycle for air dehumidification using packed beds of silica gel particles. Energy 2013, 56, 8-24. [CrossRef]

12. Feng, D.Y.; Lin, Z.; Liu, M.M.; Xie, J.; Wan, J.M.; Wang, B.; Zhou, Y.; Yang, H.L.; Zheng, H.L.; Peng, Z.Q.; et al. Silica-alumina gel humidity control beads with bimodal pore structure produced by phase separation during the sol-gel process. Microporous Mesoporous Mater. 2016, 222, 138-144. [CrossRef]

13. Ge, T.S.; Qi, D.; Dai, Y.J.; Wang, R.Z. Experimental testing on contaminant and moisture removal performance of silica gel desiccant wheel. Energy Build. 2018, 176, 71-77. [CrossRef] 
14. Huang, M.J.; Eames, P.C.; Hewitt, N.J. The application of a validated numerical model to predict the energy conservation potential of using phase change materials in the fabric of a building. Sol. Energy Mater. Sol. Cells 2006, 90, 1951-1960. [CrossRef]

15. Al-Saadi, S.N.; Zhai, Z.Q. Modeling phase change materials embedded in building enclosure: A review. Renew. Sustain. Energy Rev. 2013, 21, 659-673. [CrossRef]

16. Castellon, C.; Medrano, M.; Roca, J.; Fontanals, G.; Cabeza, L.F. Improve thermal comfort in concrete buildings by using phase change material. ASME 2007 Energy Sustain. Conf. 2007, 457-463. [CrossRef]

17. Athienitis, A.K.; Liu, C.; Hawes, D.; Banu, D.; Feldman, D. Investigation of the thermal performance of a passive solar test-room with wall latent heat storage. Build. Environ. 2014, 32, 405-410. [CrossRef]

18. Manz, H.; Egolf, P.; Suter, P.; Goetzberger, A. TIM-PCM external wall system for solar space heating and daylighting. Sol. Energy 1997, 61, 369-379. [CrossRef]

19. Ismail, K.A.R.; Castro, J.N.C. PCM thermal insulation in buildings. Int. J. Energy Res. 1997, 21, 1281-1296. [CrossRef]

20. Dardir, M.; Mankibi, M.E.; Haghighat, F.; Klimes, L. Development of PCM-to-air heat exchanger for integration in building envelope-modeling and validation. Sol. Energy 2019, 190, 367-385. [CrossRef]

21. Beltran, R.D.; Gomez, J.M. Analysis of phase change materials (PCM) for building wallboards based on the effect of environment. J. Build. Eng. 2019, 24, 100726. [CrossRef]

22. Saxena, R.; Rakshit, D.; Kaushik, S.C. Phase change material (PCM) incorporated bricks for energy conservation in composite climate: A sustainable building solution. Sol. Energy 2019, 183, 276-284. [CrossRef]

23. Fang, A.M.; Chen, Y.M.; Wu, L. Transient simulation of coupled heat and moisture transfer through multilayer walls exposed to future climate in the hot and humid southern China area. Sustain. Cities Soc. 2020, 52, 101812. [CrossRef]

24. Liu, X.W. Investigation of the Coupled Heat, Air and Moisture Transport in Building Walls in Hot Summer and Cold Winter Zone. Ph.D. Thesis, Hunan University, Changsha, China, 2015. (In Chinese).

25. Guo, X.G. Research on Coupled Heat and Moisture Transfer Characteristics of Multilayer Walls in Hot and Humid Climate. Ph.D. Thesis, Hunan University, Changsha, China, 2010. (In Chinese).

26. Kunzel, H.M. Simultaneous Heat and Moisture Transport in Building Components: One-and Two-Dimensional Calculation Using Simple Parameters; Fraunhofer IRB Verlag: Stuttgart, Germany, 2014.

27. Zhong, Z. Combined Heat and Moisture Transport Modeling for Residential Buildings; Purdue University: West Lafayette, IN, USA, 2008.

28. Li, L.P.; Wu, Z.G.; He, Y.L.; Lauriat, G.; Tao, W.Q. Optimization of the configuration of $290 \times 140 \times 90$ hollow clay bricks with 3-D numerical simulation by finite volume method. Energy Build. 2008, 40, 1790-1798. [CrossRef]

29. Yin, Y.G.; Zhang, X.S. A new method for determining coupled heat and mass transfer coefficients between air and liquid desiccant. Int. J. Heat Mass Transf. 2008, 51, 3287-3297. [CrossRef]

30. Zhou, Y.T.; Guan, Z.Q.; Gu, Y.X. Equivalent heat capacity method for solution of heat transfer with phase change. J. Chem. Ind. Eng. 2004, 55, 1428-1433. (In Chinese)

31. Liu, X.W.; Chen, Y.M.; Ge, H.; Fazio, P.; Chen, G.J. Numerical investigation for thermal performance of exterior walls of residential buildings with moisture transfer in hot summer and cold winter zone of China. Energy Build. 2015, 93, 259-268. [CrossRef]

32. Chen, Z.; Qin, M.H. Preparation and hygrothermal properties of composite phase change humidity control materials. Appl. Therm. Eng. 2016, 98, 1150-1157. [CrossRef]

33. Ge, T.S.; Dai, Y.J.; Wang, R.Z. Performance study of silica gel coated fin-tube heat exchanger cooling system based on a developed mathematical model. Energy Convers. Manag. 2011, 52, 2329-2338. [CrossRef]

34. Al-Mufti, W.M.; Hashim, U.; Adam, T. Current trend in simulation: Review nanostructures using comsol Multiphysics. J. Appl. Sci. Res. 2012, 8, 5579-5582. 
35. Talukdar, P.; Olutmayin, S.O.; Osanyintola, O.F.; Simonson, C.J. An experimental data set for benchmarking 1-D, transient heat and moisture transfer models of hygroscopic building materials. Part I: Experimental facility and material property data. Int. J. Heat Mass Transf. 2007, 50, 4527-4539. [CrossRef]

36. Talukdar, P.; Olutmayin, S.O.; Osanyintola, O.F.; Simonson, C.J. An experimental data set for benchmarking 1-D, transient heat and moisture transfer models of hygroscopic building materials. Part II: Experimental, numerical and analytical data. Int. J. Heat Mass Transf. 2007, 50, 4915-4926. [CrossRef]

(C) 2019 by the authors. Licensee MDPI, Basel, Switzerland. This article is an open access article distributed under the terms and conditions of the Creative Commons Attribution (CC BY) license (http://creativecommons.org/licenses/by/4.0/). 